\title{
Ultrasound-Guided Thoracic Paravertebral Block as a Sympathetic Blockade for Upper Extremity Neuropathic Pain: A Prospective Pilot Study
}

This article was published in the following Dove Press journal: Journal of Pain Research

\author{
Jeongsoo Kim' \\ Ho-Jin Lee $\mathbb{D}^{1,2}$ \\ Young-Ju Lee ${ }^{3}$ \\ Chang-Soon Lee ${ }^{1,2,4}$ \\ Yongjae Yoo (iD ${ }^{1,2,4}$ \\ Jee Youn Moon (ID) 1,2,4
}

'Department of Anesthesiology and Pain Medicine, Seoul National University Hospital, Seoul, Republic of Korea; ${ }^{2}$ Department of Anesthesiology and Pain Medicine, Seoul National University College of Medicine, Seoul, Republic of Korea; ${ }^{3}$ Department of Anesthesiology and Pain Medicine, SMG-SNU Boramae Medical Center, Seoul, Republic of Korea; ${ }^{4}$ Integrated Cancer Management Center, Seoul National University Cancer

Hospital, Seoul, Republic of Korea
Correspondence: Jee Youn Moon Department of Anesthesiology and Pain Medicine, Seoul National University

College of Medicine, Seoul 03080,

Republic of Korea

Tel +82-2-2072-2462

Fax +82-2-763-9390

Email jymoon090I@gmail.com
Purpose: Ultrasound-guided thoracic paravertebral block (US-TPVB) is considered a treatment option for the management of acute pain in various pain-related conditions. We conducted a prospective pilot study to evaluate the possibility of US-TPVB as a sympathetic blockade in patients with neuropathic pain disorders in the upper extremities. Patients and Methods: A total of 12 patients underwent US-TPVB between the T2 and T3 paravertebral space with $10 \mathrm{~mL}$ of $1 \%$ mepivacaine. The temperature change $\left({ }^{\circ} \mathrm{C}\right)$ before and after the procedure was compared between the ipsilateral and contralateral hands. We counted the proportion of patients showing a temperature increase $\geq 1.5^{\circ} \mathrm{C}$ and compared a change in the pain intensity before and after the procedure.

Results: The median increase in the temperature change between the ipsilateral and contralateral hands was $1.54^{\circ} \mathrm{C}$ (interquartile range, $1.28-2.20$ ). There were seven patients (58.3\%) who showed a temperature difference $\geq 1.5^{\circ} \mathrm{C}$ between both hands after the USTPVB. Eleven patients (91.7\%) reported a reduction in pain according to the score on the 11point numerical rating scale. No serious complications relevant to the procedure were reported.

Conclusion: US-TPVB could be a useful technique for sympathetic blockade in patients with upper extremity pain.

Keywords: neuropathic pain, upper extremity, paravertebral block, sympathetic block, ultrasound

\section{Introduction}

Among a plethora of various options for pain management, the sympathetic blockade has been widely used in neuropathic pain disorders, such as complex regional pain syndrome, phantom limb pain, postherpetic neuralgia, and pain due to vascular disease. $^{1,2}$ Although the exact mechanism of pain reduction from the sympathetic block is still unknown, the hyperactive sympathetic outflow and the excitatory interactions between the sympathetic nervous system, sensory neurons, and satellite glial cells have been suggested as the associated pathophysiology of sympathetically maintained pain in response to the blockade. ${ }^{3,4}$

Empirically, the stellate ganglion block (SGB) is one of the most popular sympathetic blockades to manage facial pain or pain in the upper extremities. ${ }^{5,6} \mathrm{SGB}$, however, may not always guarantee a successful outcome to control the sympathetic outflow of the upper extremity because an anatomic variant like Kuntz bypass exists, ${ }^{7}$ and the procedure usually targets the middle sympathetic ganglion at the C6 spinal level 
in practice rather than the stellate ganglion. ${ }^{5}$ Therefore, the thoracic sympathetic ganglion block (TSGB) at the T2 or T3 spinal levels could be a confirmatory technique for managing pain in the upper extremities. Compared to the SGB, the TSGB involves a complicated procedure as the needle tip should be advanced profoundly into the anterior paravertebral space. ${ }^{8}$ Thus, TSGB is usually conducted under fluoroscopy (FS) or computed tomography (CT) guidance, which results in radiation exposure and inconvenient accessibility to patients and physicians at the bedside. Furthermore, due to the long needle path adjacent to the parietal pleura during TSGB, patients frequently complain of procedure-related pain accompanied by a high risk of pneumothorax. ${ }^{9}$

The thoracic paravertebral block (TPVB) was introduced in 1905; however, it has become popular since the 2000s along with the widespread use of ultrasonography (US). ${ }^{10}$ It was proposed as a regional anesthetic technique for the management of acute postoperative pain after thoracic and breast surgery or pain due to multiple fractured ribs instead of chronic pain control. ${ }^{11-14}$ A few reports have suggested that the procedure, when performed at the T2 or T3 spinal levels, could be a potential alternative to TSGB or SGB for the management of chronic pain with a low risk of pneumothorax. ${ }^{15-18}$ Recently, Kim et al reported that the majority of patients $(80 \%)$ achieved a temperature increase $\left(\geq 1.5^{\circ} \mathrm{C}\right.$ ) on the palm after FS-guided TPVB at the T2 spinal level, which was superior to US-guided SGB $(20.0 \%){ }^{16}$ Although the US is a more popular device with easy accessibility than FS in pain practice, it is still uncertain whether such a high proportion of patients could obtain the same temperature increase after US-guided TPVB (US-TPVB).

In this study, we hypothesized that the US-TPVB could be used as a thoracic sympathetic blockade as FS-guided TPVB was suggested in a previous study. ${ }^{16}$ We conducted a prospective case-series study to explore whether USTPVB increases the temperature of the upper extremities and relieves neuropathic or neuralgic pain. This study was designed as a pilot study before a confirmatory trial to compare the effectiveness of US-TPVB to that of TSGB and SGB in various pain disorders in the upper extremities. We also included a review of the previous literature on TPVB in the management of chronic pain conditions.

\section{Patients and Methods}

\section{Study Participants}

This prospective case-series study was approved by the Institutional Review Board of Seoul National University
Hospital (IRB No. 1907-177-105) and conducted in accordance with the Declaration of Helsinki. From August 2019 to November 2019, 12 consecutive patients with chronic neuropathic pain in the upper extremities, aged 19-85 years, were included. Written informed consent was obtained from all patients prior to study participation. The exclusion criteria were as follows: (1) patients' refusal; (2) peripheral vascular disease in the upper extremity, such as atherosclerosis, thoracic outlet syndrome, or vasculitis; (3) a history of thoracic sympathetic ganglion neurolysis or radiofrequency ablation; (4) a history of lower cervical or upper thoracic spinal surgery; (5) an implanted spinal cord stimulator for management of upper extremity pain; (6) diaphragmatic paresis or severe respiratory disease; (7) systemic or local infection at the injection site; (8) coagulopathy or allergy to local anesthetics; (9) a deformation at the injection site; and (10) pregnancy.

\section{Procedure and Outcome Measurement}

All the US-TPVB procedures were performed by one pain physician (JY Moon). The patients were placed in the prone position and a doughnut-shaped cushion was applied to their forehead, if necessary. The vital signs of all the participants were monitored throughout the entire procedure. After sterilization, pre-scanning using a $1-5 \mathrm{MHz}$ round probe (UMT-400, Mindray, Shenzhen, China) was conducted to identify the T2 paravertebral space in a paravertebral sagittal image (Figure 1A). The key anatomic structures, such as the $\mathrm{T} 2$ and $\mathrm{T} 3$ transverse processes and their relevant ribs, the superior cost-transverse ligament (SCTL), and the parietal pleura, were examined before the needle was advanced (Figure 1B). Subsequently, a 22-G spinal needle (Taechang Industry, Gongju-si, Chungcheongnam-do, Republic of Korea) was inserted at about $5 \mathrm{~cm}$ from the midline into the ipsilateral T2 PVS in a caudocranial orientation with a longitudinal, oblique, in-plane technique. Once the needle was advanced to the TPVS until the SCTL was breached with a pop sensation, $10 \mathrm{~mL}$ of $1 \%$ mepivacaine was injected after negative aspiration, which was expected to spread to two segments of the TPVS, including the sympathetic ganglia. ${ }^{19-21}$ The local anesthetic was delivered slowly, followed by repeated aspiration to reduce the risk of intravascular administration. The injectate was observed to push the bright hyperechoic pleura away from the needle. After it was confirmed that the injectate was completely administered, the transducer was removed, and the sliding 

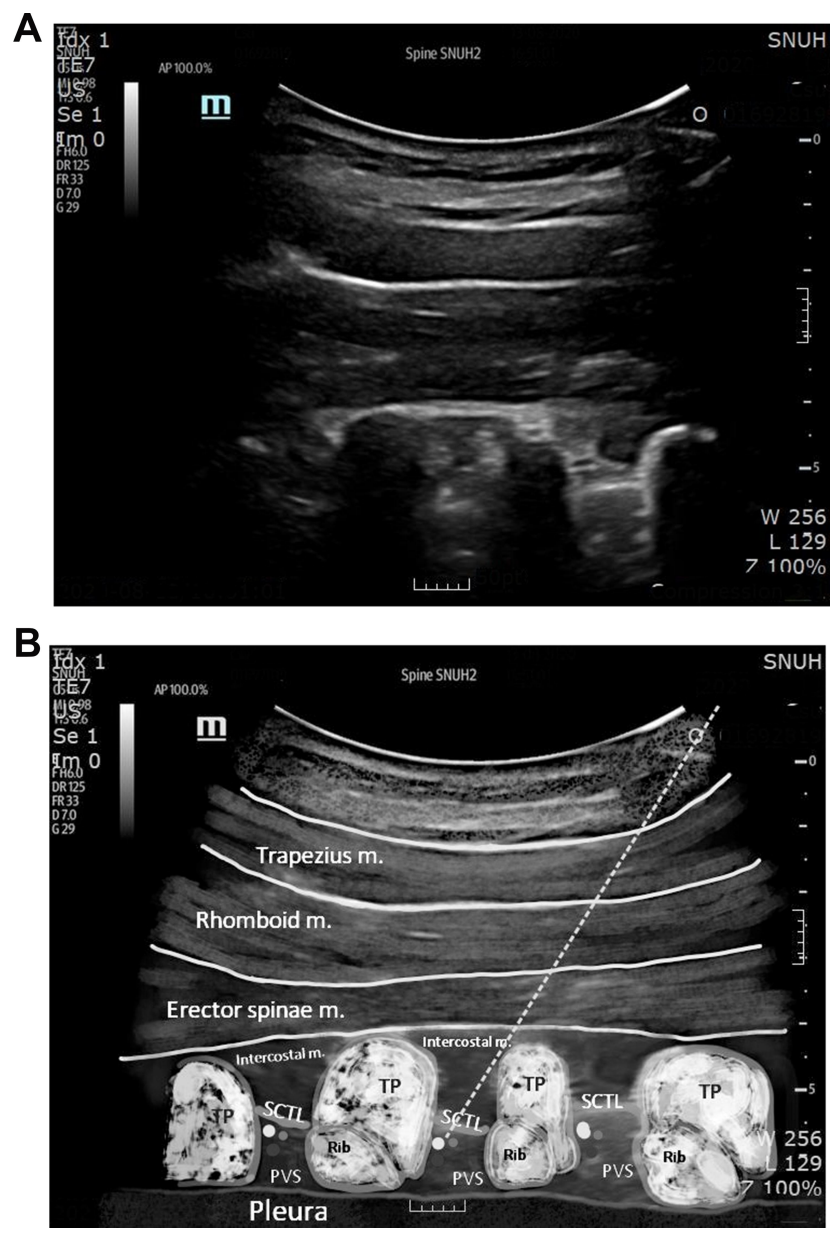

Figure I Ultrasound-guided thoracic paravertebral block in a sagittal image. Ultrasound image (A) and schematic image (B) are shown.

Notes: The dotted line indicates the entry path of the needle. After passing the $\mathrm{SCTL}, 10 \mathrm{~mL}$ of $1 \%$ mepivacaine was injected.

Abbreviations: PVS, paravertebral space; SCTL, superior costotransverse ligament; TP, transverse process; $m$, muscle.

movement of the pleura was assured. After a 30-min observation with the confirmation of no severe adverse events, the patients were allowed to leave the pain center.

The participants' temperatures were measured in both palms with an infrared imaging thermometer $\left(\mathrm{FLIR}^{\circledR}\right.$ TG165TM, The World's Sixth Sense ${ }^{\circledR}$, Wilsonville, OR, USA). The measurements were obtained immediately before and $20 \mathrm{~min}$ after the procedure by a research nurse, unaware of which side each patient received TPVB on. To ensure consistency between participants, a point $3 \mathrm{~cm}$ below the palmar aspect of the third metacarpophalangeal joint (hand) was used as a landmark. The temperature measurements were recorded at a perpendicular angle and a fixed distance of $30 \mathrm{~cm}$ with a recently calibrated infrared imaging thermometer. The difference in temperature change $\left({ }^{\circ} \mathrm{C}\right)$ between the ipsilateral and contralateral hands at $20 \mathrm{~min}$ after the US-TPVB was calculated using the formula [Post-treatment temperature of the block side Pretreatment temperature of the block side] - [Posttreatment temperature of the other side - Pretreatment temperature of the other side]. If the difference was $\geq 1.5^{\circ} \mathrm{C}$, we defined the procedure to be successful. ${ }^{22}$ The proportion of patients reaching $\geq 1.5^{\circ} \mathrm{C}$ increase in the temperature in the ipsilateral hand compared to the contralateral hand was also recorded.

Pain intensity in each patient in the upper extremity before and $20 \mathrm{~min}$ after the US-TPVB was compared using an 11-point numerical rating scale (NRS) pain score. Other information, such as the duration of pain (months), diagnosis relevant to upper extremity pain, prescribed analgesics, and other comorbidities, were also collected. The possible complications (vascular puncture, hypotension, pleural puncture, pneumothorax, seizure, ipsilateral or bilateral Horner syndrome, ipsilateral brachial plexus block, or hemidiaphragmatic paresis) ${ }^{10,23}$ were evaluated throughout the observation.

Continuous data were expressed as median (interquartile range, IQR) or mean (standard deviation, SD) and categorical data as proportions (\%).

\section{Review of Previous Studies}

The previous literature was searched to investigate TPVB in patients with neuralgic or neuropathic pain disorders. We excluded studies conducted for the purpose of preemptively controlling pain after surgery. The keywords \{"paravertebral" AND ("complex regional" OR "neuralgia" OR "neuropathic")\} were inserted in PubMed, and the relevant literature was identified. Our review was restricted to clinical studies conducted in humans and only adults aged $\geq 18$ years. Accessible articles in English and all types of studies, such as case reports, observational studies, retrospective studies, and randomized control studies, were considered. After the search, two board-certified pain physicians (J Kim and Y-J Lee) independently screened the abstracts and the titles of articles that could be eligible for this review and excluded the articles that did not match our goals.

\section{Results}

The demographic data and clinical parameters of the 12 patients in this study are shown in Table 1. Among the 12 patients, complex regional pain syndrome was the most common diagnosis $(\mathrm{n}=5)$, followed by postherpetic neuralgia $(n=4)$, peripheral nerve injury $(n=2)$, and 
Table I Demographics and Clinical Parameters of the Study Participants

\begin{tabular}{|c|c|c|c|c|c|c|c|c|c|}
\hline No. & $\begin{array}{l}\text { Age } \\
\text { (Years) }\end{array}$ & Sex & $\begin{array}{l}\text { BMI (kg/ } \\
\left.\mathbf{m}^{2}\right)\end{array}$ & $\begin{array}{l}\text { Smoking } \\
\text { (Yes/No) }\end{array}$ & Diagnosis & $\begin{array}{l}\text { Duration of Pain } \\
\text { (Months) }\end{array}$ & $\begin{array}{l}\text { Block Site } \\
\text { (Right/Left) }\end{array}$ & $\begin{array}{l}\text { Pre- } \\
\text { NRS }\end{array}$ & $\begin{array}{l}\text { Post- } \\
\text { NRS }\end{array}$ \\
\hline I & 60 & Male & 25.1 & No & $\mathrm{PHN}$ & 60 & Right & 3 & I \\
\hline 2 & 64 & Female & 24.2 & No & $\mathrm{PHN}$ & 74 & Right & 7 & 7 \\
\hline 3 & 66 & Female & 18.8 & No & PSSS & 68 & Left & 8 & 5 \\
\hline 4 & 63 & Male & 23.7 & No & $\mathrm{PNI}$ & 60 & Right & 7 & 3 \\
\hline 5 & 19 & Female & 18.1 & No & $\mathrm{PHN}$ & 48 & Left & 9 & 0 \\
\hline 6 & 60 & Female & 26.8 & No & PNI & 70 & Right & 4 & I \\
\hline 7 & 52 & Female & 30.5 & No & CRPS & 21 & Left & 6 & 2 \\
\hline 8 & 72 & Female & 24.6 & No & $\mathrm{PHN}$ & 13 & Right & 7 & I \\
\hline 9 & 41 & Male & 19.4 & Yes & CRPS & 78 & Right & 8 & 6 \\
\hline 10 & 58 & Female & 26.3 & No & CRPS & 43 & Left & 7 & 4 \\
\hline II & 42 & Male & 21.4 & Yes & CRPS & 40 & Right & 5 & 2 \\
\hline 12 & 49 & Male & 22.8 & Yes & CRPS & 28 & Right & 7 & 5 \\
\hline
\end{tabular}

Note: Pre-NRS refers to the pain intensity before the procedure, and post-NRS means the pain intensity 20 minutes after the procedure.

Abbreviations: BMI, body mass index; CRPS, complex regional pain syndrome; NRS, numerical rating scale; PHN, post-herpetic neuralgia; PNI, peripheral nerve injury; PSSS, post-spinal surgery syndrome.

postspinal surgery syndrome $(n=1)$. The median difference in the temperature change between the ipsilateral arm and the contralateral arm was $1.54^{\circ} \mathrm{C}\left(\mathrm{IQR}, 1.28-2.20^{\circ} \mathrm{C}\right)$.

A difference in temperature change $\geq 1.5^{\circ} \mathrm{C}$ between the ipsilateral and contralateral hands was detected in seven patients (58.3\%) (Figure 2). The median 11-point NRS pain score was 7 (IQR, 5.5-7.2) at baseline and decreased to 2.5 (IQR, 1.0-5.0) at $20 \mathrm{~min}$ after the US-TPVB. Overall, the patients $(n=11,92 \%)$ reported pain reduction followed by the procedure, except for one patient who reported the same pain intensity after the procedure. Ipsilateral ptosis was observed in two patients; however, there were no cases of pneumothorax, hypotension, vascular puncture, seizure, or other complications during and after the procedure.

Among a total of 92 articles searched by the keywords in PubMed, we eliminated 62 pieces of literature due to subjects irrelevant to our study and duplicate articles (Figure 3). Out of the remaining articles $(\mathrm{n}=30), 22$ were excluded because the majority of them focused on preemptive or postoperative surgical pain control $(n=18)$, two articles were not conducted in humans, one article was review literature, and one was not in English. Finally, eight articles regarding TPVB in patients with neuropathic or nerve-related pain disorders were included in our review (Table 2), which comprised a randomized cross-over study

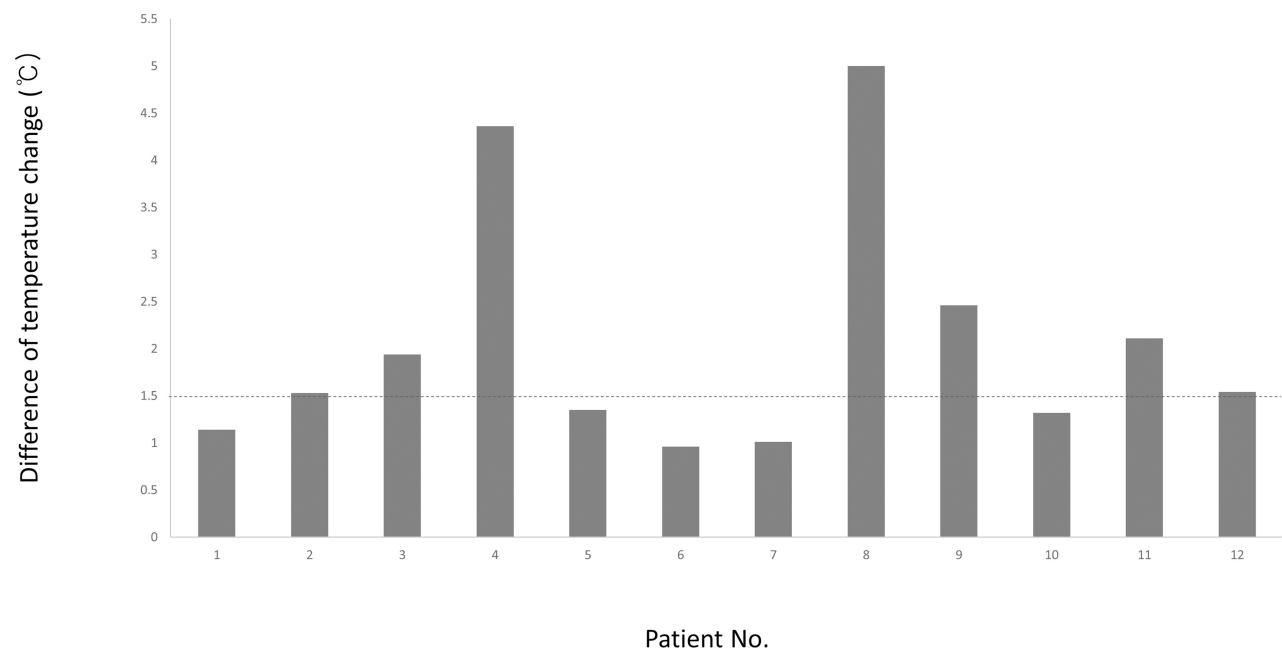

Figure 2 The difference of temperature change between the ipsilateral and contralateral hands at 20 minutes after the ultrasound-guided thoracic paravertebral block. Note: The horizontal line drawn at $1.5^{\circ} \mathrm{C}$ indicates the success criterion. 




Figure 3 Flow diagram of included previous studies.

$(\mathrm{n}=1),{ }^{16}$ randomized controlled trials $(\mathrm{n}=4),{ }^{24-27}$ a caseseries study $(\mathrm{n}=1),{ }^{28}$ and case reports $(\mathrm{n}=2) \cdot{ }^{18,29}$ Among them, three were performed on herpes zoster, ${ }^{25-27}$ two on postherpetic neuralgia, ${ }^{28,29}$ two on complex regional pain syndrome, ${ }^{16,18}$ and one on intercostal neuralgia. ${ }^{24}$ All the studies reported a reduction in the intensity of pain after the procedure. There were only two studies that used the US device during the TPVB at the affected PVS in patients with pain from postherpetic neuralgia or herpes zoster. ${ }^{27,28}$ Two studies were performed to block the thoracic sympathetic ganglia; ${ }^{16,18}$ one was conducted using an FS with a small volume of local anesthetics $(5 \mathrm{~mL}),{ }^{18}$ and the other was performed using an FS-guided TPVB to compare their effectiveness to US-guided SGB. ${ }^{16}$ The latter described that FS-guided TPVB at the T2 spinal level was more effective in blocking thoracic sympathetic ganglia with greater pain relief. ${ }^{16}$

\section{Discussion}

This prospective case-series study investigated TPVB under US guidance, with $10 \mathrm{~mL}$ of local anesthetics, as an alternative to blocking the thoracic sympathetic ganglia in chronic neuropathic pain of the upper extremities. In our study, over half of all patients $(\mathrm{n}=7,58.3 \%)$ showed a significant increase in temperature $\left(\geq 1.5^{\circ} \mathrm{C}\right)$ after the procedure. Almost all patients $(\mathrm{n}=11,92 \%)$ experienced pain reduction in their upper extremities $20 \mathrm{~min}$ after the procedure.

The thoracic paravertebral space is a potential wedgeshaped compartment adjacent to the posterolateral vertebral body. It is continuous with the intercostal space laterally and the epidural space medially. The dorsal and ventral branches of the spinal nerve and intercostal nerve traverse posteriorly to the paravertebral space. Anteriorly, it contains the rami communicantes, hemi-azygos vein, and sympathetic trunk. $^{10,30,31}$ Hence, the TPVB could produce ipsilateral, segmental, somatic, and sympathetic nerve blockade. In addition, the space extends cranially and caudally, ${ }^{19,32}$ which was the case in at least two patients of our study, resulting in Horner syndrome with ptosis after US-TPVB. Previous cadaver studies demonstrated that US-guided injection with $10-20 \mathrm{~mL}$ of contrast dye was visible in the intercostal space to the sympathetic chain with cranial and caudal extensions. ${ }^{19,32}$ In those studies, the paravertebral spreads of contrast media were highly variable, which might contribute significantly to analgesic effects in each patient. Besides, the approach may affect the spread of the injectates in USTPVB, as reported in a recent cadaveric study. ${ }^{33}$ In the study, an intercostal approach covered the intercostal area rather than reaching the sympathetic chain anteriorly. ${ }^{33}$ So far, previous clinical and cadaveric studies have focused on the intercostal and epidural spreading for managing postoperative or acute pain rather than blocking the sympathetic chain. ${ }^{19,30,32}$ Therefore, it was necessary to investigate whether TPVB could be used as the thoracic sympathetic blockades for the management of chronic pain. Our result suggests the possibility of US-TPVB at the T2 and T3 spinal levels to be used for the TSGB. 
Table 2 Previous Studies of Paravertebral Block for Neuropathic or Nerve-Related Pain

\begin{tabular}{|c|c|c|c|c|c|c|c|}
\hline & Dx & $\begin{array}{l}\text { Study } \\
\text { Design }\end{array}$ & $\begin{array}{l}\text { Groups } \\
\text { (N) }\end{array}$ & Device & Technique & Dose & Outcome \\
\hline $\begin{array}{l}\text { Kim } \\
\text { et } \text { al }^{16}\end{array}$ & CRPS & $\begin{array}{l}\text { Randomized } \\
\text { cross-over } \\
\text { study }\end{array}$ & $\begin{array}{l}\text { GI: SGB } \\
\text { (15) } \\
\text { G2: } \\
\text { TPVB } \\
\text { (15) }\end{array}$ & $\begin{array}{l}\text { US for } \\
\text { SGB, FS } \\
\text { for } \\
\text { TPVB }\end{array}$ & $\begin{array}{l}\text { SGB at the } \\
\text { C6 level } \\
\text { TPVB at the } \\
\text { T2 level }\end{array}$ & $\begin{array}{l}\text { SGB: } 5 \mathrm{~mL} \text { of } 1 \% \text { LDC } \\
\text { TPVB: } 10 \mathrm{~mL} \text { of } 1 \% \\
\text { LDC }\end{array}$ & 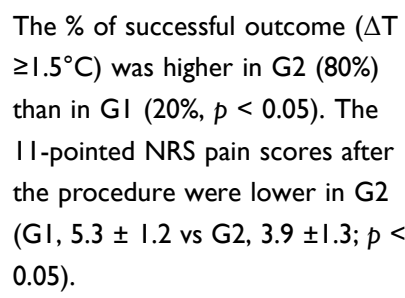 \\
\hline $\begin{array}{l}\text { Xiao } \\
\text { et } \mathrm{al}^{24}\end{array}$ & $\begin{array}{l}\text { Intercostal } \\
\text { neuralgia }\end{array}$ & RCT & $\begin{array}{l}\text { GI: PG } \\
(30) \\
\text { G2: } \\
\text { TPVB } \\
(30) \\
\text { G3: PG } \\
+ \text { TPVB } \\
(30)\end{array}$ & NSt & $\begin{array}{l}\text { TPVB at the } \\
\text { affected PVS }\end{array}$ & $\begin{array}{l}\text { PG: } 150-600 \mathrm{mg} / \text { day } \\
\text { TPVB: } 20 \mathrm{~mL}(\mathrm{NS}+ \\
0.75 \% \text { RPV } 5 \mathrm{~mL}+ \\
\text { betamethasone I mL + } \\
\text { Vitamin BI2 I mg) }\end{array}$ & $\begin{array}{l}\text { After } 6 \text { weeks, The VAS pain score } \\
\text { in G3 was lower than those in } G 2 \\
\text { and } G \text { I (GI, } 26.5 \pm 0.7 \text { vs } G 2,34.5 \\
\pm 0.7 \text { vs G3, } 12.4 \pm 0.9 ; p<0.005)\end{array}$ \\
\hline $\begin{array}{l}\text { Gungor } \\
\text { et al }{ }^{18}\end{array}$ & CRPS & Case report & $N=1$ & FS & $\begin{array}{l}\text { TPVB at the } \\
\text { T2 PVS }\end{array}$ & $5 \mathrm{~mL}$ of $0.125 \% \mathrm{BPV}$ & $\begin{array}{l}\text { The successful sympathetic } \\
\text { blockade was achieved }\left(\Delta \mathrm{T}>2.0^{\circ}\right. \\
\text { C), and pain and tingling senses } \\
\text { were reduced by } 50 \% \text { immediately } \\
\text { after the procedure. }\end{array}$ \\
\hline $\begin{array}{l}\text { Zhao } \\
\text { et } \mathrm{al}^{28}\end{array}$ & PHN & Case series & $N=27$ & US & $\begin{array}{l}\text { TPVB at the } \\
\text { affected PVS }\end{array}$ & $\begin{array}{l}10 \mathrm{~mL}(\mathrm{NS}+0.2 \% \\
\text { methylene blue } 2 \mathrm{~mL}+ \\
0.75 \% \text { RPV } 5 \mathrm{~mL})\end{array}$ & $\begin{array}{l}\text { The VAS pain score was decreased } \\
\text { from } 7.6 \pm 1.5 \text { to } 1.6 \pm 1.3 \text { at } 2 \\
\text { weeks }(p<0.05)\end{array}$ \\
\hline $\begin{array}{l}\text { Naja } \\
\text { et } \mathrm{al}^{29}\end{array}$ & PHN & Case report & $N=1$ & NSt & $\begin{array}{l}\text { TPVB at the } \\
\text { TI PVS (a } \\
\text { bolus) and } \\
\text { T3 PVS (via } \\
\text { a catheter) }\end{array}$ & $\begin{array}{l}20 \mathrm{~mL}(0.5 \% \text { BPV } 19 \mathrm{~mL} \\
+150 \mu \text { clonidine } 1 \mathrm{~mL}) \\
\text { injected through } \\
\text { a catheter every } 48 \\
\mathrm{~h} \text { for } 3 \text { weeks }\end{array}$ & $\begin{array}{l}\text { The patients with } 7-8 / 10 \text { on the } \\
\text { VAS pain score at baseline } \\
\text { achieved pain-free after the } \\
\text { procedure for an } 8 \text {-month follow- } \\
\text { up period. }\end{array}$ \\
\hline $\begin{array}{l}\text { Makharita } \\
\text { et } \mathrm{al}^{25}\end{array}$ & $\mathrm{HZ}$ & RCT & $\begin{array}{l}\text { GI: } \\
P(68) \\
\text { G2: } \\
\text { TPVB } \\
(70)\end{array}$ & FS & $\begin{array}{l}\text { TPVB at the } \\
\text { affected PVS }\end{array}$ & $\begin{array}{l}\text { P: } 10 \mathrm{~mL} \text { NS } \\
\text { TPVB: } 10 \mathrm{~mL}(\mathrm{NS}+ \\
8 \mathrm{mg} \text { dexamethasone + } \\
0.5 \% \text { BPV } 5 \mathrm{~mL})\end{array}$ & $\begin{array}{l}\text { The VAS pain score was lower in } \\
\text { the G2 at } 3 \text { weeks }(\mathrm{GI}, \mathrm{I} .5 \pm \mathrm{I} .9 \\
\text { vs } \mathrm{G} 2,0.5 \pm \mathrm{I} .4 ; p<0.00 \mathrm{I}) \text {. Total } \\
\text { PG and AAP consumptions were } \\
\text { reduced in } \mathrm{G} 2 \text { vs GI (both } p< \\
0.00 \mathrm{I} \text { ). }\end{array}$ \\
\hline Ji et $\mathrm{al}^{26}$ & $\mathrm{HZ}$ & RCT & $\begin{array}{l}\text { GI: } \\
M(68) \\
\text { G2: } M+ \\
\text { PVB (64) }\end{array}$ & $\begin{array}{l}\text { NSt } \\
\text { (PVB) }\end{array}$ & $\begin{array}{l}\text { PVB: } \\
\text { Affected } \\
\text { PVS }\end{array}$ & $\begin{array}{l}\text { M: } 800 \mathrm{mg} \text { acyclovir } 5 \\
\text { times } / \mathrm{d} \text { for } 7 \text { days }+ \\
\text { diclofenac } 50 \mathrm{mg} \text { up to } \\
4 \text { times } / \mathrm{d} \\
\text { PVB: } 10 \mathrm{~mL}(0.25 \% \mathrm{BPV} \\
+40 \mathrm{mg} \text { methyl- } \\
\text { prednisolone) injected } \\
\text { every } 48 \mathrm{~h} \text { for a week }\end{array}$ & $\begin{array}{l}\text { The \% of patients with pain } \\
\text { decreased in G2 than GI at I } \\
\text { month (GI, } 45 \% \text { vs G2, I3\%; } p< \\
0.00 \mathrm{I} \text { ). The incidence of PHN also } \\
\text { decreased, and at } 12 \text { months, the } \\
\% \text { of patients with pain was } \\
\text { different (GI, } 16 \% \text { vs G2, } 2 \% \text {; } p< \\
0.05 \text { ). }\end{array}$ \\
\hline
\end{tabular}

(Continued) 
Table 2 (Continued).

\begin{tabular}{|c|c|c|c|c|c|c|c|}
\hline & Dx & $\begin{array}{l}\text { Study } \\
\text { Design }\end{array}$ & $\begin{array}{l}\text { Groups } \\
\text { (N) }\end{array}$ & Device & Technique & Dose & Outcome \\
\hline $\begin{array}{l}\text { Zhao } \\
\text { et } \mathrm{al}^{27}\end{array}$ & $\mathrm{HZ}$ & RCT & $\begin{array}{l}\text { GI: } \\
\text { M (44) } \\
\text { G2: M+ } \\
\text { TPVB } \\
(43)\end{array}$ & US & $\begin{array}{l}\text { TPVB at the } \\
\text { affected PVS }\end{array}$ & $\begin{array}{l}\text { M: antiviral drug and } \\
\text { nutritional therapy } \\
\text { TPVB: } 10 \mathrm{~mL}(0.2 \% \\
\text { methylene blue } 2 \mathrm{~mL}+ \\
0.75 \% \text { RPV } 5 \mathrm{~mL}+\mathrm{NS})\end{array}$ & $\begin{array}{l}\text { The VAS pain score decreased at I } \\
\text { week in G2 than GI }(G I, 5.9 \pm 1.5 \\
\text { vs G2, } 2.9 \pm 1.6 ; p<0.05) \text {. }\end{array}$ \\
\hline
\end{tabular}

Note: Values are presented as mean \pm standard deviation or a number or proportion (\%).

Abbreviations: AAP, acetaminophen; BPV, bupivacaine; CRPS, complex regional pain syndrome; FS, fluoroscopy; G, group; HZ, herpes zoster; LDC, lidocaine; M, medication; NRS, numerical rating scale; NS, normal saline; NSt, nerve stimulator; P, placebo; PG, pregabalin; PHN, postherpetic neuralgia; PVB, paravertebral block; PVS, paravertebral space; RCT, randomized controlled trial; RPV, ropivacaine; SGB, stellate ganglion block; TPVB, thoracic paravertebral block; US, ultrasound; VAS, visual analogue scale.

In order to perform a sympathetic blockade of the upper extremity, US-guided SGB or FS-guided TSGB has been mainly implemented. ${ }^{34,35}$ However, SGB is incomplete due to Kuntz bypass ${ }^{36,37}$ and TSGB has a higher risk of pneumothorax because the needle should reach the anterior paravertebral space (Figure 4). ${ }^{10,20}$ For this reason, TSGB usually requires FS guidance. Otherwise, US-TPVB has an advantage for physicians and patients as it is conducted at the bedside without radiation exposure. In addition, TPVB targets the posterior paravertebral space, which lowers the risk of complications, such as pneumothorax. However, because the thoracic sympathetic ganglia are located anteriorly in the paravertebral space, blockade of these ganglia after US-TPVB is uncertain. In our study, after US-TPVB using $10 \mathrm{~mL}$ of local anesthetics, only seven participants (58.3\%) showed an increase $\geq 1.5^{\circ} \mathrm{C}$ on their ipsilateral hands compared to the contralateral hands, which was considered as a meaningful increase after sympathetic blockade in previous studies. ${ }^{5,16,22}$ Presumably, $10 \mathrm{~mL}$ of local anesthetics would not be enough to reach the target sympathetic ganglia in some cases. Therefore, future studies could be conducted to investigate the adequate volume of injectates enough to soothe thoracic sympathetic ganglia during the US-TPVB because higher volumes of local anesthetics are commonly used during the US-guided procedure in the thoracic paravertebral areas. ${ }^{30,38}$

Our brief review noted a few studies reporting the effectiveness of TPVB in treating several neuropathic or

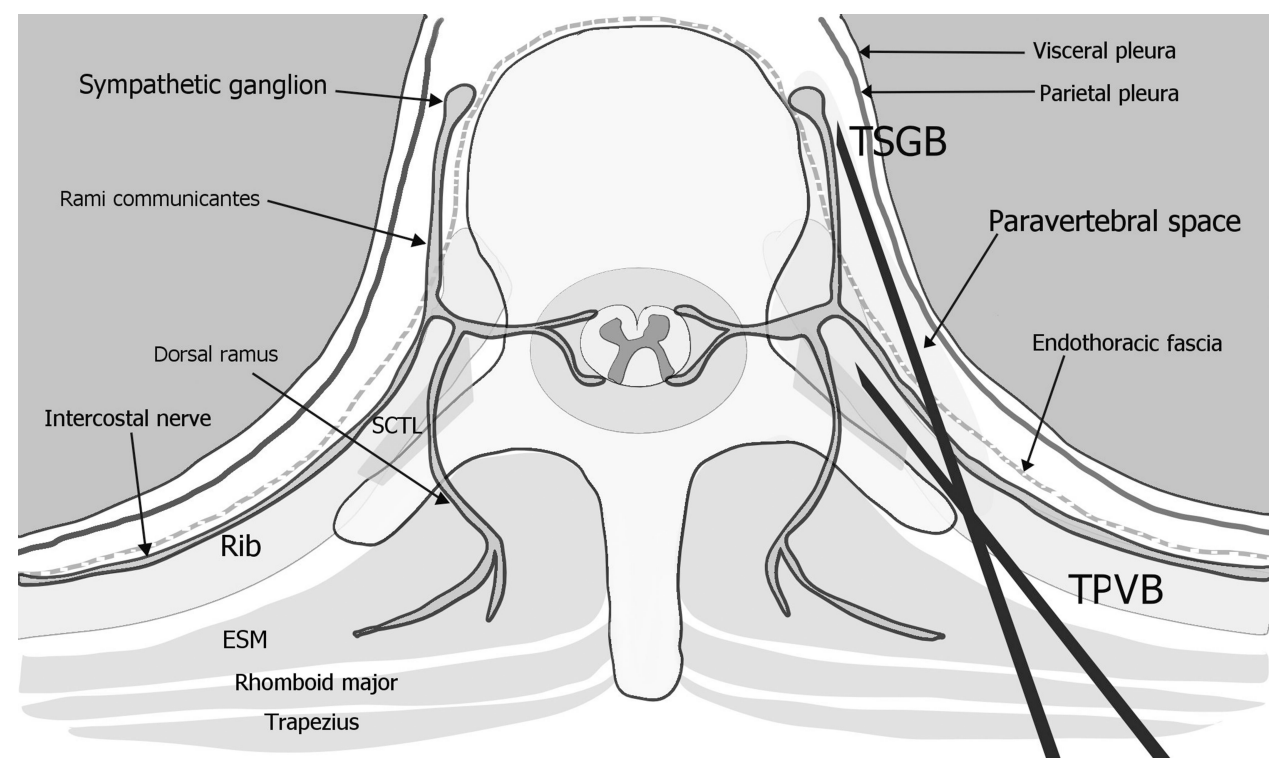

Figure 4 Schematic axial image of the thoracic paravertebral space.

Note: The needle of the TPVB towards the posterior paravertebral space, and the needle of the TSGB towards the sympathetic ganglia at the anterior paravertebral space. Abbreviations: ESM, erector spinae muscle; SCTL, superior costotransverse ligament; TPVB, thoracic paravertebral block; TSGB, thoracic sympathetic ganglion block. 
nerve-related pain (Table 2). Among those pieces of literature, a recent study by Kim et al described that FS-guided TPVB using $10 \mathrm{~mL}$ of $1 \%$ lidocaine achieved a temperature increase $\geq 1.5^{\circ} \mathrm{C}$ in $80 \%$ of subjects $(n=12 / 15)$. ${ }^{16}$ They used the same volume $(10 \mathrm{~mL})$ as that of our study. However, technically, all injectates were administered after confirming needle tips using contrast media under FS guidance, which might result in higher success rates in their study. Otherwise, using the US, real-time imaging helps physicians detect the location of the needle tip. However, during the procedure, an initial volume of the injectates may quickly spread outside the superior costotransverse ligament, out of the paravertebral space. In this case, the physicians need to advance the needle a little further, and subsequently, the remaining volume should be administered. We suggest that US-TPVB should be performed in two steps, such as initial hydro-dissection with normal saline $(<1 \mathrm{~mL})$ to verify the needle position followed by the second step of injection with local anesthetics, which could improve the accuracy of the procedure.

This study has several limitations. First, it was a case series report with a narrative review to show the possibility of US-TPVB as an alternative to TSGB. Therefore, the head-tohead studies to compare US-TPVB and TSGB or SGB are necessary with reasonable sample size. Second, among several sympathetic functions, we applied only a difference in temperature changes using infrared thermography. The other measurements using the changes in skin conductance or the amount of sudomotor activity could help confirm the complete sympathetic blockade after the procedure. ${ }^{39}$ Third, in terms of the technical issue, we advanced the needle using a longitudinal parasagittal image in a caudocranial orientation. The other technique, such as using a lateral-to-medial approach in a transverse image, should be investigated to achieve the same result. Although almost all the patients in this study, who were diagnosed with neuropathic or nerverelated pain in their upper extremities, reported pain reduction at 20 min after the block, the clinical and long-term effectiveness of US-TPVB should be investigated in various chronic pain conditions.

\section{Conclusion}

In conclusion, although further confirmatory studies are warranted, this case-series study suggested that US-TPVB might be a useful method for managing patients with neuropathic pain in the upper extremity.

\section{Acknowledgments}

We are grateful to all the doctors and nurses for their help.

\section{Disclosure}

The authors declare no conflicts of interest.

\section{References}

1. Day M. Sympathetic blocks: the evidence. Pain Pract. 2008;8 (2):98-109. doi:10.1111/j.1533-2500.2008.00177.x

2. Choi E, Nahm FS, Lee PB. Sympathetic block as a new treatment for lymphedema. Pain Physician. 2015;18(4):365-372.

3. Chen SS, Zhang JM. Progress in sympathetically mediated pathological pain. J Anesth Perioper Med. 2015;2(4):216-225. doi:10.24015/ JAPM.2015.0029

4. Hanani M, Spray DC. Emerging importance of satellite glia in nervous system function and dysfunction. Nat Rev Neurosci. 2020;21 (9):485-498. doi:10.1038/s41583-020-0333-Z

5. Yoo Y, Lee CS, Kim YC, Moon JY, Finlayson RJ. A randomized comparison between 4, 6 and $8 \mathrm{ml}$ of local anesthetic for ultrasound-guided stellate ganglion block. J Clin Med. 2019;8 (9):1314. doi:10.3390/jcm8091314

6. Kim J, Park HS, Cho SY, Baik HJ, Kim JH. The effect of stellate ganglion block on intractable lymphedema after breast cancer surgery. Korean J Pain. 2015;28(1):61-63. doi:10.3344/kjp.2015.28.1.61

7. Marhold F, Izay B, Zacherl J, Tschabitscher M, Neumayer C. Thoracoscopic and anatomic landmarks of Kuntz's nerve: implications for sympathetic surgery. Ann Thorac Surg. 2008;86 (5):1653-1658. doi:10.1016/j.athoracsur.2008.05.080

8. Dondelinger R, Kurdziel J. Percutaneous phenol block of the upper thoracic sympathetic chain with computed tomography guidance: a new technique. Acta Radiol. 1987;28(5):511-515. doi:10.1177/ 028418518702800503

9. Stanton-Hicks M. Complications of sympathetic blocks for extremity pain. Tech Reg Anesth Pain Manag. 2007;11(3):148-151. doi:10.1053/j.trap.2007.05.007

10. Karmakar MK. Thoracic paravertebral block. Anesthesiology. 2001;95(3):771-780. doi:10.1097/00000542-200109000-00033

11. Hwang BY, Kim E, Kwon JY, et al. The analgesic efficacy of a single injection of ultrasound-guided retrolaminar paravertebral block for breast surgery: a prospective, randomized, double-blinded study. Korean J Pain. 2020;33(4):378-385. doi:10.3344/kjp.2020.33.4.378

12. Vogt A, Stieger D, Theurillat C, Curatolo M. Single-injection thoracic paravertebral block for postoperative pain treatment after thoracoscopic surgery. Br J Anaesth. 2005;95(6):816-821. doi:10.1093/bja/ aei250

13. Moller JF, Nikolajsen L, Rodt SA, Ronning H, Carlsson PS. Thoracic paravertebral block for breast cancer surgery: a randomized double-blind study. Anesth Analg. 2007;105(6):1848-1851. doi:10.1213/01.ane.0000286135.21333.fd

14. Mohta M, Verma P, Saxena AK, Sethi AK, Tyagi A, Girotra G. Prospective, randomized comparison of continuous thoracic epidural and thoracic paravertebral infusion in patients with unilateral multiple fractured ribs - a pilot study. J Trauma Acute Care Surg. 2009;66 (4):1096-1101. doi:10.1097/TA.0b013e318166d76d

15. Pace MM, Sharma B, Anderson-Dam J, Fleischmann K, Warren L, Stefanovich P. Ultrasound-guided thoracic paravertebral blockade: a retrospective study of the incidence of complications. Anesth Analg. 2016;122(4):1186-1191. doi:10.1213/ANE.0000000000001117

16. Kim ED, Kim SY, Lee YJ, Kim ED, Prospective A. Randomized cross-over trial of T2 paravertebral block as a sympathetic block in complex regional pain syndrome. Pain Physician. 2019;22:E417E424. 
17. Taketa Y, Fujitani T. Ultrasound-guided high-thoracic paravertebral block relieves referred pain caused by cervical spondylosis and provides stellate ganglion-blocking effect. $J$ Clin Anesth. 2016;34:490-491. doi:10.1016/j.jclinane.2016.06.002

18. Gungor S, Brar J. Epidural approach to paravertebral thoracic sympathetic block as an alternative to stellate ganglion block: a case report. Medicine (Baltimore). 2018;97(28):e11492. doi:10.1097/ MD.0000000000011492

19. Cowie B, McGlade D, Ivanusic J, Barrington MJ. Ultrasound-guided thoracic paravertebral blockade: a cadaveric study. Anesth Analg. 2010;110(6):1735-1739. doi:10.1213/ANE.0b013e3181dd58b0

20. Krediet AC, Moayeri N, van Geffen G-J, et al. Different approaches to ultrasound-guided thoracic paravertebral block. An illustrated review. Anesthesiology. 2015;123(2):459-474. doi:10.1097/ ALN.0000000000000747

21. Marhofer D, Marhofer P, Kettner SC, et al. Magnetic resonance imaging analysis of the spread of local anesthetic solution after ultrasound-guided lateral thoracic paravertebral blockade. A volunteer study. Anesthesiology. 2013;118(5):1106-1112. doi:10.1097/ALN.0b013e318289465f

22. Stevens RA, Stotz A, Kao T-C, Powar M, Burgess S, Kleinman B. The relative increase in skin temperature after stellate ganglion block is predictive of a complete sympathectomy of the hand. Reg Anesth Pain Med. 1998;23(3):266-270.

23. Renes SH, van Geffen GJ, Snoeren MM, Gielen MJ, Groen GJ. Ipsilateral brachial plexus block and hemidiaphragmatic paresis as adverse effect of a high thoracic paravertebral block. Reg Anesth Pain Med. 2011;36(2):198-201. doi:10.1097/AAP.0b013e31820d424c

24. Xiao P, Zhu X, Wu X. Curative effect research on curing intercostal neuralgia through paravertebral nerve block combined with pregabalin. Pak J Pharm Sci. 2014;27(5):1645-1649.

25. Makharita MY, Amr YM, El-Bayoumy Y. Single paravertebral injection for acute thoracic herpes zoster: a randomized controlled trial. Pain Pract. 2015;15(3):229-235. doi:10.1111/papr.12179

26. Ji G, Niu J, Shi Y, Hou L, Lu Y, Xiong L. The effectiveness of repetitive paravertebral injections with local anesthetics and steroids for the prevention of postherpetic neuralgia in patients with acute herpes zoster. Anesth Analg. 2009;109(5):1651-1655. doi:10.1213/ ANE.0b013e3181b79075

27. Zhao P, Mei L. A clinical study of paraspinal nerve block on treatment of herpes zoster under ultrasonic guidance. Neurochirurgie. 2019;65(6):382-386. doi:10.1016/j.neuchi.2019.06.007
28. Zhao P, Mei L, Wang W. Clinical study of ultrasound-guided methylene blue thoracic paravertebral nerve block for the treatment of postherpetic neuralgia. Turk Neurosurg. 2019;29(6):811-815.

29. Naja ZM, Maaliki H, Al-Tannir MA, El-Rajab M, Ziade F, Zeidan A. Repetitive paravertebral nerve block using a catheter technique for pain relief in post-herpetic neuralgia. $B r J$ Anaesth. 2006;96 (3):381-383. doi:10.1093/bja/ael007

30. Pawa A, Wojcikiewicz T, Barron A, El-Boghdadly K. Paravertebral blocks: anatomical, practical, and future concepts. Curr Anesthesiol Rep. 2019;9(3):263-270. doi:10.1007/s40140-019-00328-x

31. Batra RK, Krishnan K, Agarwal A. Paravertebral block. J Anaesthesiol Clin Pharmacol. 2011;27(1):5-11.

32. Ruscio L, Renard R, Lebacle C, Zetlaoui P, Benhamou D, Bessede T. Thoracic paravertebral block: comparison of different approaches and techniques. A study on 27 human cadavers. Anaesth Crit Care Pain Med. 2020;39(1):53-58. doi:10.1016/j.accpm.2019.04.003

33. Taketa Y, Fujitani T. Approach affects injectate spread in ultrasound-guided thoracic paravertebral block: a cadaveric trial. $\mathrm{Br}$ J Anaesth. 2017;119(2):339-340. doi:10.1093/bja/aex209

34. Baig S, Moon JY, Shankar H. Review of sympathetic blocks: anatomy, sonoanatomy, evidence, and techniques. Reg Anesth Pain Med. 2017;42(3):377-391. doi:10.1097/AAP.0000000000000591

35. Yoo HS, Nahm FS, Lee PB, Lee CJ. Early thoracic sympathetic block improves the treatment effect for upper extremity neuropathic pain. Anesth Analg. 2011;113(3):605-609.

36. Kuntz A. Distribution of the sympathetic rami to the brachial plexus: its relation to sympathectomy affecting the upper extremity. Arch Surg. 1927;15(6):871-877. doi:10.1001/archsurg.1927.01130240 044003

37. Hogan QH, Taylor ML, Goldstein M, Stevens R, Kettler R. Success rates in producing sympathetic blockade by paratracheal injection. Clin J Pain. 1994;10(2):139-145. doi:10.1097/00002508-19940600 0-00008

38. Adhikary SD, Bernard S, Lopez H, Chin KJ. Erector spinae plane block versus retrolaminar block: a magnetic resonance imaging and anatomical study. Reg Anesth Pain Med. 2018;43(7):756-762.

39. Gungor S, Rana B, Fields K, et al. Changes in the skin conductance monitor as an end point for sympathetic nerve blocks. Pain Med. 2017;18(11):2187-2197. doi:10.1093/pm/pnw318
Journal of Pain Research

\section{Publish your work in this journal}

The Journal of Pain Research is an international, peer reviewed, open access, online journal that welcomes laboratory and clinical findings in the fields of pain research and the prevention and management of pain. Original research, reviews, symposium reports, hypothesis formation and commentaries are all considered for publication. The manuscript

Submit your manuscript here: https://www.dovepress.com/journal-of-pain-research-journa management system is completely online and includes a very quick and fair peer-review system, which is all easy to use. Visit http:// www.dovepress.com/testimonials.php to read real quotes from published authors. 